\title{
Induction of Heme Oxygenase-1 Inhibits the Monocyte Transmigration Induced by Mildly Oxidized LDL
}

\author{
Kazunobu Ishikawa, Mohamad Navab, Norbert Leitinger, Alan M. Fogelman, and Aldons J. Lusis \\ Department of Medicine, Division of Cardiology, UCLA School of Medicine, Los Angeles, California 90095-1679
}

\begin{abstract}
Heme catabolic processes produce the antioxidants biliverdin and bilirubin, as well as the potent prooxidant free iron. Since these products have opposing effects on oxidative stress, it is not clear whether heme catabolism promotes or inhibits inflammatory processes, including atherosclerotic lesion formation. Heme oxygenase (HO) catalyzes the rate-limiting step of heme catabolism. We used cocultures of human aortic endothelial cells and smooth muscle cells to examine the possible role of $\mathrm{HO}$ in early atherosclerosis. Heme oxygenase-1 (HO-1), the inducible isoform of $\mathrm{HO}$, was highly induced by mildly oxidized LDL, and augmented induction was observed with hemin pretreatment. This augmented HO-1 induction resulted in the reduction of monocyte chemotaxis in response to LDL oxidation. Conversely, inhibition of $\mathrm{HO}$ by a specific inhibitor, Sn-protoporphyrin IX, enhanced chemotaxis. Furthermore, pretreatment with biliverdin or bilirubin, the products of $\mathrm{HO}$, reduced chemotaxis. Oxidized phospholipids in the mildly oxidized LDL appear to be responsible for HO-1 induction, since oxidized but not native arachidonic acid-containing phospholipids also induced HO-1. These results suggest that $\mathrm{HO}-1$ induced by mildly oxidized LDL may protect against the induction of inflammatory responses in artery wall cells through the production of the antioxidants biliverdin and bilirubin. (J. Clin. Invest. 1997. 100:1209-1216.) Key words: coculture • biliverdin • bilirubin • gene expression $\bullet$ atherosclerosis
\end{abstract}

\section{Introduction}

Microsomal heme oxygenase $(\mathrm{HO})^{1}$ is the rate-limiting enzyme for heme degradation in mammals (1). HO decomposes heme into biliverdin and releases free iron and carbon monox-

Address correspondence to Dr. Aldons J. Lusis, Department of Medicine, UCLA School of Medicine, Los Angeles, CA 90095-1679. Phone: 310-794-7297; FAX: 310-794-7345; E-mail: jlusis@medicine.medsch. ucla.edu

Received for publication 24 February 1997 and accepted in revised form 22 May 1997.

1. Abbreviations used in this paper: CM-LDL, coculture-modified LDL; CO, carbon monoxide; HAEC, human aortic endothelial cells; HASMC, human aortic smooth muscle cells; HO, heme oxygenase; PAPC, 1-palmitoyl-2-arachidonyl-sn-glycero-3-phosphorylcholine; PGPC, 1-palmitoyl-2-glutaryl-sn-glycero-3-phosphorylcholine; PIPPC, 1-palmitoyl-2-isoprostanoyl-sn-glycero-3-phosphorylcholine; POVPC, 1-palmitoyl-2-(5-oxovaleryl)-sn-glycero-3-phosphorylcholine; SnPP IX, Sn-protoporphyrin IX.

J. Clin. Invest.

(C) The American Society for Clinical Investigation, Inc. 0021-9738/97/09/1209/08 \$2.00

Volume 100, Number 5, September 1997, 1209-1216

http://www.jci.org ide (CO). Two isoforms of $\mathrm{HO}$ have been identified, which exhibit differences in regulation and tissue localization (2-4). $\mathrm{HO}-1$ is an inducible form that is transcriptionally upregulated by a variety of chemical or physical stress-inducing factors such as heavy metals (5), certain organic compounds (5), hydrogen peroxide (6), heat shock (2), ultraviolet (UV) irradiation (6), cytokines $(7,8)$, hypoxia (9), hyperoxia (10), as well as its substrate, heme (11). Many of these stresses are not directly involved in heme metabolism, raising the question of why HO-1 responds to these factors and conditions. As 11-12 mol of $\mathrm{NADPH}$ are consumed in the $\mathrm{HO}$ reaction to reduce heme iron or to activate molecular oxygen, it seems reasonable to assume that HO-1 has a critical and beneficial role for the cells under conditions of oxidative stress (12).

Heme, the substrate for the HO reaction, is released from senescent hemoglobin in the spleen. However, HO is expressed in many cells, presumably because heme synthesis and degradation is necessary for cytochromes and other heme-containing enzymes such as catalase or nitric oxide synthase. Heme itself is a prooxidant which exhibits acute cytotoxicity (13). Therefore, prompt HO-1 induction after exposure to various oxidants is needed for cellular protection. In addition, the products of heme degradation, bilirubin and biliverdin, can act as antioxidants $(14,15)$. Biliverdin is reduced by cytosolic biliverdin reductase in mammals (16). Thus, HO has been postulated to participate in defense mechanisms against oxidative injury by agents such as endotoxin, metals, and certain cytokines (17-20). We provide evidence here that HO may protect against the proinflammatory effects of LDL oxidation in the artery wall. Previous studies have shown that biliverdin and bilirubin have the ability to inhibit the oxidation of linoleic acid and LDL in vitro and that their antioxidant capacities are stronger than that of $\alpha$-tocopherol (21-24). CO, another reaction product of $\mathrm{HO}$, is endogenously produced during this reaction. Several lines of study have shown that CO may have biological activity similar to nitric oxide in brain and blood vessels via the activation of the soluble form of guanylate cyclase which results in the elevation of intracellular cGMP levels (3, 25-29).

Formation of oxidatively modified LDL in the subendothelial space of the artery wall has been implicated in the pathogenesis of atherosclerosis and may be a major source of free radical insult to the artery wall (30-33). The mechanisms contributing to LDL oxidation in the artery wall appear to involve seeding by oxidative waste from vascular cells $(34,35)$. In contrast, the mechanisms of endogenous prevention of LDL oxidation other than those related to HDL, or exogenous antioxidants like probucol (36) or $\alpha$-tocopherol (37) are not generally well understood. It was recently reported using in vitro studies that oxidized LDL triggers expression of HO-1, heat shock protein 70 (HSP 70), macrophage stress protein 23 (MSP23), and a $150-\mathrm{kD}$ oxygen-regulated protein (ORP150) as stress proteins in vascular endothelial cells, vascular smooth muscle cells, macrophages, and renal tubular epithelial cells (38-41). However, the functions of these stress proteins are unknown. 
In this study, we examined the induction of HO-1 by mildly oxidized LDL and oxidized AA-containing phospholipids in an artery wall model $(42,43)$. Monocyte chemotaxis induced by mildly oxidized LDL is a key step in the formation of an initial atheromatous plaque and is dependent on the activation of several chemotactic factors by mildly oxidized LDL (42, 44, 45). Our data demonstrate that augmentation of HO-1 resulted in the inhibition of oxidized LDL-induced monocyte chemotaxis and that, in contrast, inhibition of HO-1 resulted in the promotion of monocyte chemotaxis. We additionally observed that biliverdin and bilirubin were involved in this inhibition of monocyte chemotaxis, possibly by acting as antioxidants. These data are the first evidence that HO-1 may inhibit the inflammatory response characteristic of the early atherosclerotic lesion.

\section{Methods}

Reagents. Tissue culture media, serum, and supplements were obtained from sources previously reported (21). Hemin chloride (type III), gelatin (endotoxin-free, tissue culture grade, \#G 9391), deferoxamine mesylate, and authentic L- $\alpha$-1-palmitoyl-2-arachidonyl-sn-glycero-3-phosphorylcholine (PAPC) were obtained from Sigma Chemical Co. (St. Louis, MO). Sn-protoporphyrin IX (SnPP IX), biliverdin, and bilirubin were obtained from Porphyrin Products, Inc. (Logan, UT). The preparation of hemin, SnPP IX, biliverdin, and bilirubin was performed in the dark since they are sensitive to light. All other reagents used were obtained from Sigma Chemical Co. unless otherwise specified.

Cell cultures. Human aortic endothelial cells (HAEC) and smooth muscle cells (HASMC) were isolated from healthy heart donor aortic specimens as previously described $(42,43)$. For coculture preparation, HASMC were seeded at a confluent density of $10^{5}$ cells $/ \mathrm{cm}^{2}$ in gelatinized flasks or 96-well plates, and cultured for $3 \mathrm{~d}$ to cover the entire surface of the flasks or wells and to produce a substantial amount of extracellular matrix. HAEC were subsequently seeded over the matrix at $10^{5}$ cells $/ \mathrm{cm}^{2}$ and allowed to grow, forming a complete monolayer of confluent endothelial cells within $2 \mathrm{~d}$. In all experiments, HAEC and HASMC were used at passages 4-6.

Lipoprotein isolation and modification. LDL $(d=1.019-1.069 \mathrm{~g} / \mathrm{ml})$ was isolated from the sera of normal blood donors by density gradient ultracentrifugation as described, and stored at $4^{\circ} \mathrm{C}$ until use within $1-2$ wk of isolation (46). Lipoprotein-deficient serum $(d>1.21 \mathrm{~g} / \mathrm{ml})$ was kept frozen and used within 2-4 mo. Lipoprotein concentrations are expressed in terms of protein content throughout this report. The concentration of endotoxin in the lipoprotein solutions was $<50 \mathrm{pg} /$ $\mathrm{ml}$ (determined by a chromogenic assay), which is 50 -fold less than that required to induce monocyte transmigration. Coculture-modified LDL (CM-LDL) was prepared by incubating freshly prepared LDL for $24 \mathrm{~h}$ in cocultures maintained in $10 \%$ lipoprotein-deficient serum (42). Apo B degradation and modification were not detectable in CM-LDL as judged by SDS-PAGE followed by silver staining (data not shown). Previous studies with in vitro mildly modified LDL have also failed to reveal evidence for apo B degradation (47). TBARS were $<3 \mathrm{nmol} / \mathrm{MDA}$ equivalent/mg LDL, conjugated dienes $<0.3$ absorbance units at $234 \mathrm{~nm}$, and LOOH $<1.5 \mathrm{ng} 13 \mathrm{~S}$ HPODE/ $/ \mathrm{g}$ LDL in the CM-LDL preparations used (data not shown). CM-LDL has been shown to have biological and chemical properties very similar to those of minimally oxidized LDL, which also contains bioactive lipids (47-49).

Preparation of oxidized phospholipids. Oxidized PAPC was prepared by the autoxidation of authentic PAPC for $48 \mathrm{~h}$ in air at room temperature. The extent of oxidation was monitored by positive ion flow injection electrospray mass spectrometry (49). Biologically active phospholipids, 1-palmitoyl-2-glutaryl-sn-glycero-3-phosphorylcholine (PGPC, m/z 610), 1-palmitoyl-2-(5-oxovaleryl)-sn-glycero-3-phosphoryl- choline (POVPC, m/z 594), and 1-palmitoyl-2-isoprostanoyl-sn-glycero3-phosphorylcholine (PIPPC, m/z 829), ${ }^{2}$ in oxidized PAPC were isolated by preparative normal phase HPLC and electrospray mass spectrometry (50).

Monocyte chemotaxis assay. Blood monocytes were obtained from a pool of healthy donors as previously described (51). Monocyte transmigration was determined using the previously described method $(42,43)$. Cocultures were pretreated with hemin chloride in M199 medium containing 2\% FCS for $16 \mathrm{~h}$. Cocultures were subsequently washed twice with the same medium and treated with conditioned medium containing CM-LDL for an additional $16 \mathrm{~h}$. Pretreatment with SnPP IX, deferoxamine, biliverdin, and bilirubin was performed $2 \mathrm{~h}$ before the addition of CM-LDL. Cocultures were washed twice $2 \mathrm{~h}$ after pretreatment and then treated with conditioned medium containing CM-LDL and the compounds added during pretreatment. Monocytes were labeled with the fluorescent probe Dil (1,1'-dioctadecyl-3,3,3',3'-tetramethyl-indo-carbocyanine perchlorate) at $4^{\circ} \mathrm{C}$ for $10 \mathrm{~min}$, and washed. The cell pellet was resuspended in M199 medium at the appropriate density. At the end of the second 16-h treatment of cocultures, labeled monocytes were added at $2.5 \times$ $10^{5}$ cells $/ \mathrm{cm}^{2}$ and incubated for $60 \mathrm{~min}$ at $37^{\circ} \mathrm{C}$. The medium containing nonadherent cells was then removed, and the cell layers were washed at $37^{\circ} \mathrm{C}$ to remove the loosely adherent cells on top of the endothelial monolayer. The cocultures were fixed, mounted, and subendothelial monocytes were enumerated under a magnification of 625 . In pilot experiments, the supernatants from cocultures were tested for chemotactic activity using a standard Neuroprobe chamber (Neuro Probe, Inc., Cabin John, MD). Experiments using hemin, SnPP IX, biliverdin, and bilirubin were performed in the dark since these substances are photosensitive.

RNA extraction and Northern blot analysis. Total RNA was isolated with TRIzol reagent (GIBCO BRL, Gaithersburg, MD) from HAEC, HASMC, and cocultures. $20 \mu \mathrm{g}$ total RNA was electrophoresed in a formaldehyde $/ 1 \%$ agarose gel, then transferred to MagnaGraph nylon membrane (Micron Separations, Westborough, MA) and cross-linked to the membrane by UV irradiation. The blots were prehybridized for $30 \mathrm{~min}$ and hybridized with ${ }^{32} \mathrm{P}$-labeled rat $\mathrm{HO}-1$ cDNA (52) for $60 \mathrm{~min}$ at $60^{\circ} \mathrm{C}$ in Rapid-hyb buffer (Amersham Corp., Arlington Heights, IL). The blots were washed in $2 \times \mathrm{SSC}$, $0.1 \% \mathrm{SDS}$ at room temperature for $20 \mathrm{~min}$ and then twice in $1 \times \mathrm{SSC}$, $0.1 \% \mathrm{SDS}$ at $65^{\circ} \mathrm{C}$ for $15 \mathrm{~min}$. Blots were dried and exposed to $\mathrm{Hy}-$ perfilm ${ }^{\mathrm{TM}}$-ECL (Amersham Corp.) with an intensifying screen at $-70^{\circ} \mathrm{C}$. Densitometric analysis of HO-1 mRNA expression was performed and standardized with $\alpha$-actin RNA.

Heme oxygenase assay. Heme oxygenase activity was measured with the microsomal fractions of coculture cells by determining the level of bilirubin formation $(15,52)$. Cocultures were treated with 350 $\mu \mathrm{g} / \mathrm{ml}$ native LDL, CM-LDL, or $5 \mu \mathrm{M}$ hemin for $16 \mathrm{~h}$, or pretreated with $5 \mu \mathrm{M}$ hemin followed by $350 \mu \mathrm{g} / \mathrm{ml} \mathrm{CM-LDL}$, or were pretreated with $10 \mu \mathrm{M}$ SnPP IX followed by $350 \mu \mathrm{g} / \mathrm{ml}$ CM-LDL. Cells were then washed twice with phosphate-buffered saline $(\mathrm{pH}$ 7.4) and scraped with a rubber policeman. The cell suspension was centrifuged at $1,000 \mathrm{~g}$ for $10 \mathrm{~min}$ at $4^{\circ} \mathrm{C}$. The cell pellet was homogenized and centrifuged at $18,000 \mathrm{~g}$ for $10 \mathrm{~min}$. The supernatant solution was centrifuged at 100,000 $\mathrm{g}$ for $60 \mathrm{~min}$. Microsomal fractions were resuspended in $100 \mathrm{mM}$ potassium phosphate buffer ( $\mathrm{pH} 7.4$ ) containing $2 \mathrm{mM}$ $\mathrm{MgCl}_{2}$. Microsomes (500 $\mu \mathrm{g}$ protein) were incubated with hemin (30 $\mu \mathrm{M})$, pig liver cytosol $(2 \mathrm{mg} / \mathrm{ml})$, glucose-6-phosphate dehydrogenase (0.2 U), glucose-6-phosphate $(2 \mathrm{mM})$, and NADPH $(0.8 \mathrm{mM})$ in 0.5 $\mathrm{ml}$ for $30 \mathrm{~min}$ at $37^{\circ} \mathrm{C}$ in the dark. The formed bilirubin was extracted with chloroform, and the absorbance of bilirubin at $464 \mathrm{~nm}$ was measured against a baseline absorbance at $528 \mathrm{~nm}$ (extinction coefficient, $40 \mathrm{mM}^{-1} \mathrm{~cm}^{-1}$ for bilirubin). Heme oxygenase activity is expressed as

2. Preliminary studies suggest that the oxidized phospholipid with $\mathrm{m} / \mathrm{z}$ 829 is an isoprostane-like molecule corresponding to PIPPC. However, further confirmation of the precise structure is required. 
A

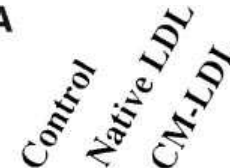

B

$\begin{array}{lllllll}0 & 1 & 4 & 12 & 24 & 48 & \text { (h) }\end{array}$

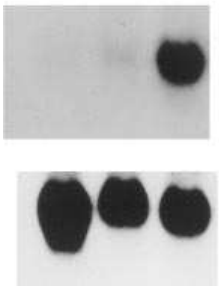

HO1

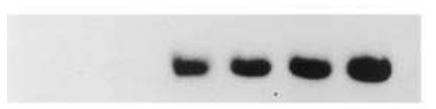

HO1

C $\quad 0 \quad 100 \quad 200300400500$

CM-LDL (mg/ml)

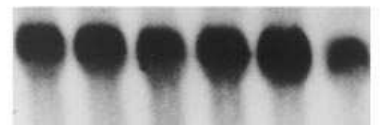

$\alpha$-actin

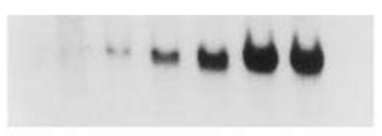

HO1

Figure 1. HO-1 mRNA induction by CM-LDL in endothelial and smooth muscle cell cocultures. Total RNA (20 $\mu \mathrm{g})$ was prepared from coculture cells, and Northern blot analysis was performed. Data shown represent three independent experiments. ( $A$ ) HO- 1 induction by native LDL and CM-LDL. Coculture cells were exposed to native LDL $(350 \mu \mathrm{g} / \mathrm{ml})$ or CM-LDL $(350 \mu \mathrm{g} / \mathrm{ml})$ for $6 \mathrm{~h}$. CM-LDL was prepared by incubation of native LDL for $16 \mathrm{~h}$ in other coculture cells. $(B)$ Time course of HO-1 induction by CM-LDL. Coculture cells were exposed to CM-LDL (350 $\mu \mathrm{g} / \mathrm{ml}$ ) for 0, 1, 4, 12, 24, and $48 \mathrm{~h}$. (C) Dose-dependent HO-1 induction by CM-LDL. Coculture cells were exposed to CM-LDL at 0, 100, 200, 300,400 , and $500 \mu \mathrm{g} / \mathrm{ml}$ for $6 \mathrm{~h}$. Relative change of HO-1 mRNA expression was determined by laser densitometric analysis and normalized by $\alpha$-actin mRNA.

$\mathrm{pmol}$ of bilirubin formed $/ \mathrm{mg}$ protein $/ 60 \mathrm{~min}$. The protein content of microsomes was determined by the method of Lowry (53) with BSA as a standard.

Data analysis. All values are expressed as mean \pm SEM. Significant difference was determined by one-way ANOVA.

\section{Results}

HO-1 induction by oxidized LDL in coculture cells. To examine HO-1 gene response to LDL and mildly oxidized LDL, we performed Northern blot analyses in HAEC and HASMC cocultures. Fig. $1 A$ shows the changes in HO-1 mRNA levels after treatment with native LDL and LDL mildly oxidized by cellular exposure (CM-LDL) for $6 \mathrm{~h}$. Untreated cocultures had no basal expression of $\mathrm{HO}-1$, and cocultures treated with 350 $\mu \mathrm{g} / \mathrm{ml}$ native LDL had little induction. In contrast, HO-1 mRNA was highly induced after treatment with $350 \mu \mathrm{g} / \mathrm{ml}$ CM-LDL. We then determined the time course of HO-1 induction by CM-LDL in cocultures (Fig. 1 B). HO-1 induction was apparent $4 \mathrm{~h}$ after incubation with CM-LDL, and mRNA

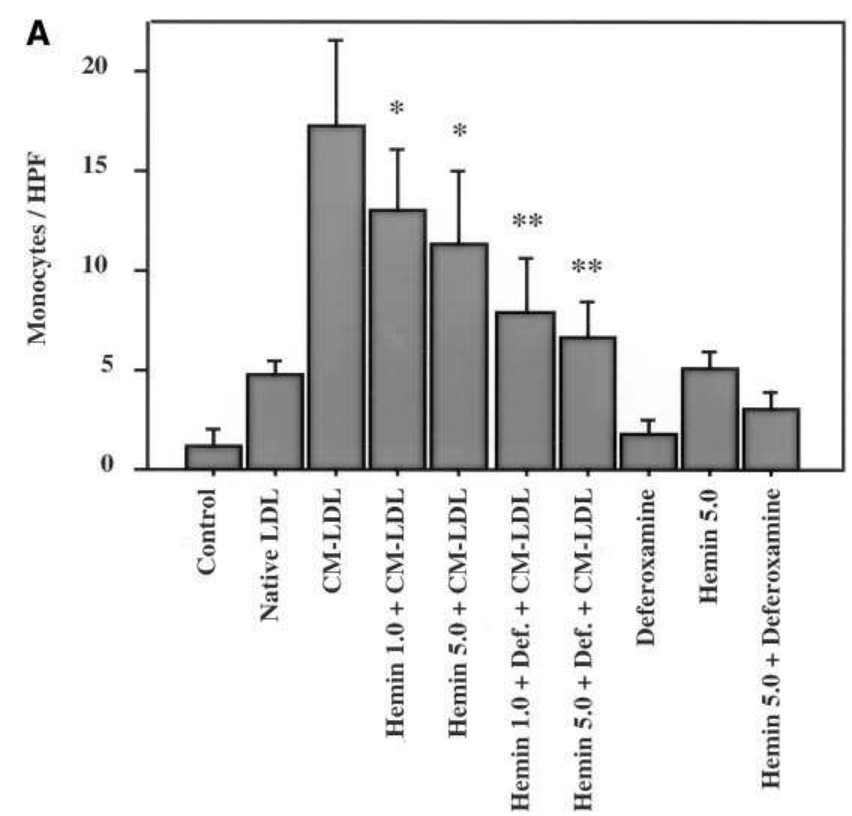

B

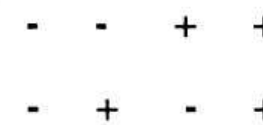

$-+\quad+$
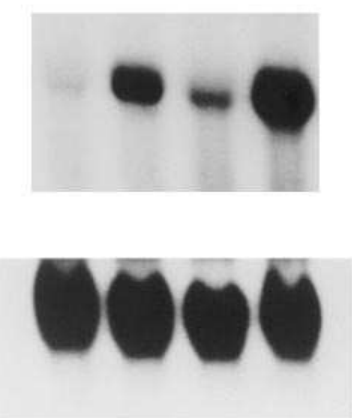

Hemin pretreatment

CM-LDL

HO1

$\alpha-$ actin

Figure 2. (A) Pretreatment with hemin attenuates monocyte chemotaxis induced by CM-LDL. Coculture cells were pretreated with 1.0 or 5.0 $\mu \mathrm{M}$ hemin with or without deferoxamine $(250 \mu \mathrm{M})$ for $16 \mathrm{~h}$ to induce HO-1. Then, cells were exposed to CM-LDL (350 $\mu \mathrm{g} / \mathrm{ml}) \mathrm{for}$ another $16 \mathrm{~h}$. Native LDL $(350 \mu \mathrm{g} / \mathrm{ml})$ was used as control. Conditioned medium was collected, and monocyte transmigration assay was performed. Values are mean \pm SD of the number of monocytes. Asterisks represent statistically significant differences compared to CM-LDL treatment $(* P<0.001)$ and to hemin + CM-LDL treatment $(* * P<0.001)$. Def., deferoxamine mesylate. $(B)$ Alteration of HO-1 induction by hemin pretreatment in cocultures. Cocultures were pretreated with $5 \mu \mathrm{M}$ hemin for $16 \mathrm{~h}$ followed by exposure to CM-LDL ( $350 \mu \mathrm{g} / \mathrm{ml})$ for $6 \mathrm{~h}$. Total RNA was prepared, and Northern blot analysis was performed. Data shown represent three independent experiments. 
continued to accumulate for $48 \mathrm{~h}$. HO-1 was induced by CMLDL in a dose-dependent fashion between 0 and $400 \mu \mathrm{g} / \mathrm{ml}$ (Fig. $1 C$ ).

Effect of HO-1 expression on CM-LDL-induced monocyte chemotaxis in artery wall cocultures. Monocyte infiltration of the artery wall appears to be involved in the onset and progression of atherosclerotic lesion formation $(42,44,45)$. Balla et al. (13) reported that endothelial cells can rapidly take up low concentrations of hemin without cellular injury, and that endothelial cells pretreated with hemin exhibit an induction of HO-1 mRNA. To augment the expression of HO-1, we pretreated cocultures with 1 and $5 \mu \mathrm{M}$ hemin in $2 \%$ serum containing M199 medium for $16 \mathrm{~h}$. After cells were washed, pretreated cocultures were exposed to $350 \mu \mathrm{g} / \mathrm{ml} \mathrm{CM-LDL}$ for $16 \mathrm{~h}$ followed by the monocyte chemotactic assay (Fig. $2 A$ ). Hemin pretreatment significantly attenuated CM-LDL-induced chemotaxis compared to no pretreatment $(P<0.001)$. Cytotoxicity was not obvious at these levels of hemin and CM-LDL (data not shown).

Deferoxamine is a hydrophilic iron chelator which crosses the plasma membrane. As HO releases free iron in the reaction, we tested the effect of iron chelation by deferoxamine on monocyte chemotaxis. Addition of $250 \mu \mathrm{M}$ deferoxamine during hemin pretreatment resulted in further attenuation of oxidized LDL-induced chemotaxis. Hemin itself had mild chemotactic activity, probably due to the effect of hemin itself or iron released from hemin.

To confirm HO-1 induction in the artery wall cocultures, HO-1 induction was evaluated by Northern blot analysis (Fig. $2 B$ ). CM-LDL treatment induced $\mathrm{HO}-1$ by 15 -fold, $5-\mu \mathrm{M}$ hemin pretreatment 5-fold, and pretreatment with hemin fol-

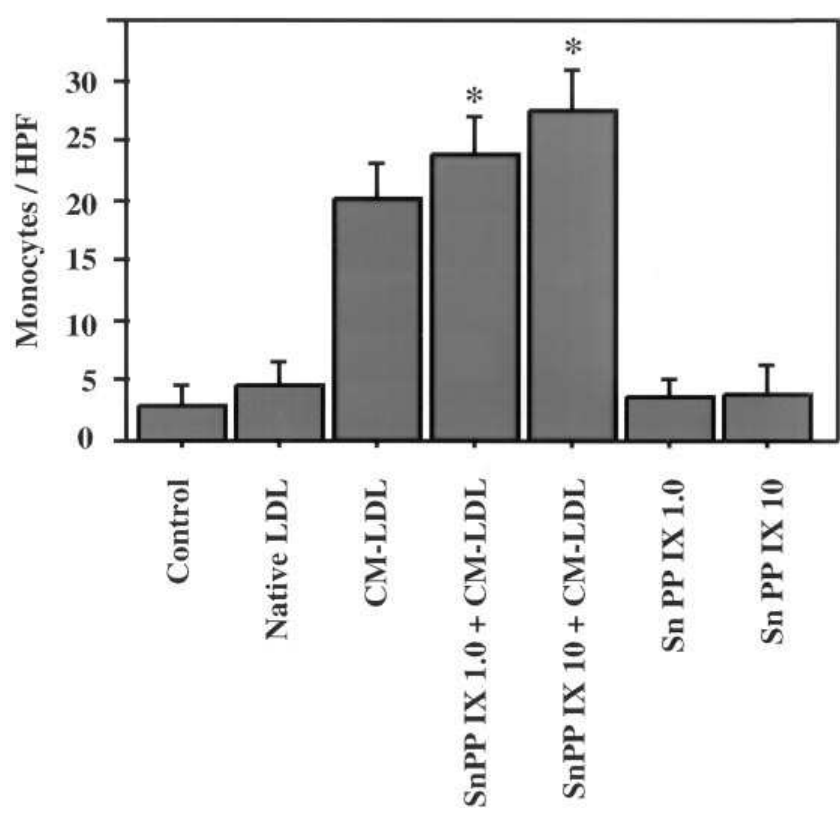

Figure 3. Pretreatment with SnPP IX enhances monocyte chemotaxis induced by CM-LDL. Coculture cells were pretreated with 1.0 or $10 \mu \mathrm{M}$ SnPP IX for $2 \mathrm{~h}$ to inhibit HO-1. Then, cells were exposed to CM-LDL $(350 \mu \mathrm{g} / \mathrm{ml})$ with SnPP IX for another $16 \mathrm{~h}$. Native LDL $(350 \mu \mathrm{g} / \mathrm{ml})$ was used as control. Conditioned medium was collected, and the monocyte transmigration assay was performed. Values are mean \pm SD of the number of monocytes. *Statistically significant differences from CM-LDL treatment $(P<0.001)$. lowed by CM-LDL treatment up to 61-fold. This confirmed the augmentation of HO-1 induction by hemin pretreatment. To eliminate the possibility that the augmented induction of HO-1 is due to residual membrane-bound hemin which is potentiating the further oxidation of CM-LDL, we examined the biological activity of CM-LDL produced by cocultures pretreated with hemin as compared to that produced by control (not pretreated) cocultures. Briefly, we pretreated one set of cocultures with $5 \mu \mathrm{M}$ hemin for $16 \mathrm{~h}$, followed by washing, and another set was mock-treated. Both cocultures were then exposed to $350 \mu \mathrm{g} / \mathrm{ml} \mathrm{CM-LDL}$ for $16 \mathrm{~h}$. The conditioned media were then collected and used to treat fresh sets of cocultures for $8 \mathrm{~h}$. The resulting conditioned media were then used for monocyte chemotaxis assays. We did not observe any difference in chemotactic activity between these two sets of final conditioned media (data not shown). These results suggest that the hemin pretreatment did not result in further modification of CM-LDL.

We then used a specific HO-1 inhibitor, SnPP IX, to examine whether inhibition of HO-1 affects CM-LDL-induced monocyte chemotaxis (Fig. 3). Cocultures were pretreated with SnPP IX at 1 or $10 \mu \mathrm{M}$ for $2 \mathrm{~h}$. Cells were then exposed to 350 $\mu \mathrm{g} / \mathrm{ml} \mathrm{CM-LDL} \mathrm{and} \mathrm{SnPP} \mathrm{IX} \mathrm{at} 1$ or $10 \mu \mathrm{M}$ for $16 \mathrm{~h}$ followed by the chemotaxis assay. SnPP IX pretreatment promoted CM-LDL-induced monocyte chemotaxis compared to CMLDL treatment alone. To determine the changes in HO-1 activity by pretreatment, we measured $\mathrm{HO}$ activity in microsomes from coculture cells (Table I). Cells pretreated with hemin followed by CM-LDL contained 2.3-fold higher levels of HO-1 activity compared to cells treated with CM-LDL alone, while cells pretreated with SnPP IX followed by CMLDL had only $39 \%$ of the activity of the cells treated with CMLDL alone.

Augmented induction of HO-1 by hemin pretreatment occurs in endothelial but not smooth muscle cells. We then determined which cell type is responsible for the augmentation of HO-1 induction by hemin pretreatment (Fig. 4). Endothelial or smooth muscle cell monolayer derived from the same donor was cultured separately or in combination, and the changes in HO-1 mRNA levels were examined under the experimental conditions used in Fig. $2 \mathrm{~B}$. In endothelial cells, we observed HO-1 induction by CM-LDL and its augmentation by hemin

Table I. Changes in HO Enzyme Activity in Endothelial and Smooth Muscle Cell Cocultures

\begin{tabular}{lc}
\hline \multicolumn{1}{c}{ Conditions } & HO activity \\
\hline & pmol bilirubin/mg protein/h \\
Control cells & $33 \pm 4$ \\
Native LDL & $59 \pm 5$ \\
CM-LDL & $665 \pm 62$ \\
Hemin & $154 \pm 35$ \\
Hemin + CM-LDL & $1536 \pm 101$ \\
SnPP IX + CM-LDL & $259 \pm 46$
\end{tabular}

Cocultures were treated with $350 \mu \mathrm{g} / \mathrm{ml}$ native LDL, CM-LDL, or $5 \mu \mathrm{M}$ hemin for $16 \mathrm{~h}$, pretreated with $5 \mu \mathrm{M}$ hemin followed by $350 \mu \mathrm{g} / \mathrm{ml} \mathrm{CM-}$ LDL, or pretreated with $10 \mu \mathrm{M}$ SnPP IX followed by $350 \mu \mathrm{g} / \mathrm{ml} \mathrm{CM-}$ LDL. HO activity was measured by microsomal fraction of coculture cells. Data shown are the results of four independent experiments in duplicate. 
pretreatment (Fig. $4 A$ ), consistent with the results of coculture studies. In contrast, whereas HO-1 mRNA was also induced by CM-LDL, there was no augmentation by hemin pretreatment in smooth muscle cells (Fig. $4 \mathrm{~B}$ ). Cells from three different donors exhibited this difference in response between endothelial and smooth muscle cells. We conclude that endothelial but not smooth muscle cells exhibit augmented HO-1 induction by hemin pretreatment, and that endothelial cells may be responsible for the attenuated monocyte chemotaxis after hemin pretreatment.

Attenuation of CM-LDL-induced chemotaxis by biliverdin and bilirubin. Biliverdin is a product of the HO-1 reaction, bilirubin is its metabolite, and both were shown to inhibit lipid peroxidation in vitro (21-24). However, their effects on endothelial-monocyte interactions have not been examined. We treated cocultures with biliverdin or bilirubin at 7.5 or $15 \mu \mathrm{M}$ for $2 \mathrm{~h}$ and then treated the cocultures with $350 \mu \mathrm{g} / \mathrm{ml} \mathrm{CM}-\mathrm{LDL}$ together with biliverdin or bilirubin followed by the chemotaxis assay (Fig. 5). Both biliverdin and bilirubin treatments attenuated CM-LDL-induced monocyte chemotaxis. These data suggest that biliverdin and bilirubin may play a role in moderating the CM-LDL-induced monocyte chemotaxis.

HO-1 induction by oxidized phospholipids. PAPC is one of the phospholipids present in LDL. We showed previously that

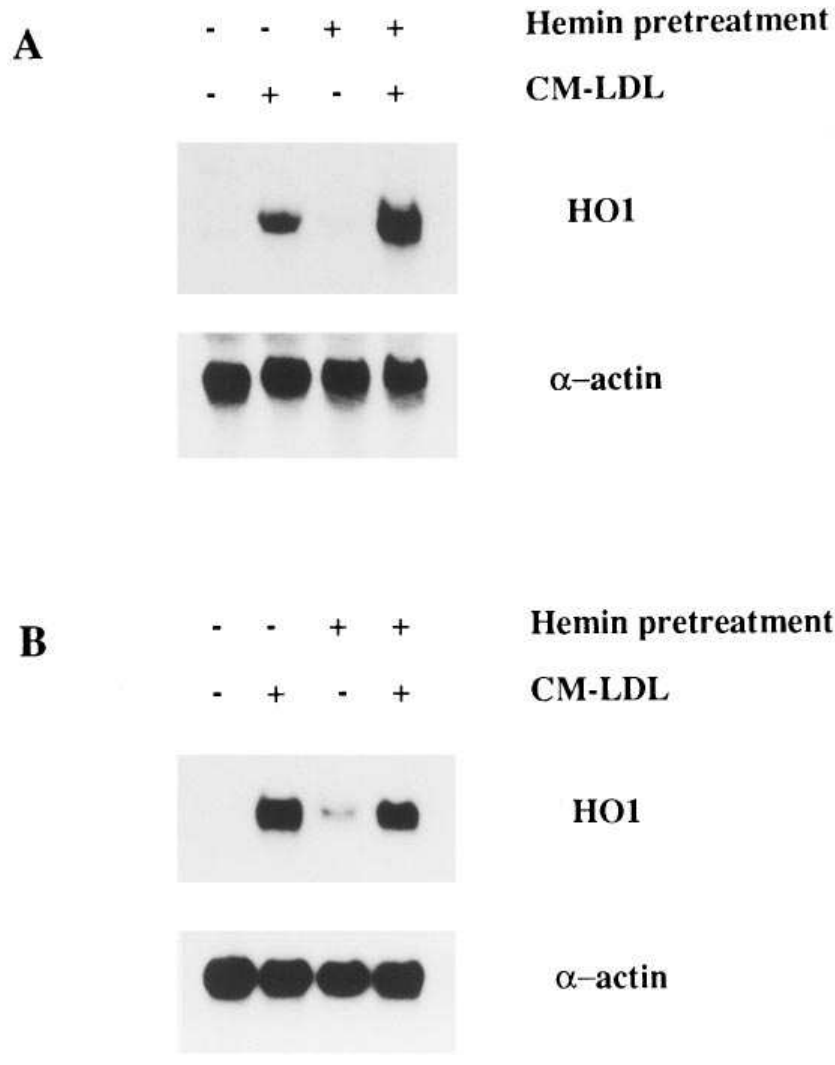

Figure 4. Different induction of HO-1 by hemin pretreatment in human aortic endothelial and smooth muscle cells. Cultures were pretreated with $5.0 \mu \mathrm{M}$ hemin for $16 \mathrm{~h}$ and then exposed to CM-LDL $(350 \mu \mathrm{g} / \mathrm{ml})$ for $6 \mathrm{~h}$. HO-1 mRNA induction was examined by Northern blot analysis. $(A)$ Human aortic endothelial cells. $(B)$ Human aortic smooth muscle cells. Data shown represent three independent experiments from different donors. oxidized PAPC has the same biological activities as mildly oxidized LDL (49). As shown in Fig. 6 A, HO-1 mRNA was not induced by $100 \mu \mathrm{g} / \mathrm{ml}$ native PAPC, but was induced by 100 $\mu \mathrm{g} / \mathrm{ml}$ oxidized PAPC. Augmentation of HO-1 induction by hemin pretreatment followed by oxidized PAPC treatment was also observed, similar to the results with CM-LDL treatment. We next examined three isolated oxidized phospholipids from oxidized PAPC which were recently shown to have biological activity (50), including the ability to activate endothelial cells to bind monocytes, to determine whether these oxidized phospholipids induce HO-1 mRNA (Fig. 6 B). PIPPC was the most potent inducer of HO-1, and PGPC also induced HO-1 mRNA in cocultures, whereas POVPC did not induce HO-1 at $10 \mu \mathrm{g} / \mathrm{ml}$. The concentrations of the oxidized phospholipids used here were sufficient to activate endothelial cells to bind monocytes (50).

\section{Discussion}

Cocultures of HAEC and HASMC provide a model for analysis of the molecular and cellular events in early atherogenesis $(42,43)$. These cocultures have an abundant extracellular matrix derived from endothelial and smooth muscle cells, they preserve interactions between endothelial and smooth muscle cells, and they provide a microenvironment which allows LDL oxidation even in the presence of serum $(49,54)$. In such cocultures, HO-1 was not expressed in basal conditions and was not induced by native LDL, but it was dramatically induced by mildly oxidized LDL (CM-LDL) (Fig. 1). This induction was dose dependent, and mRNA continued to accumulate for at least $48 \mathrm{~h}$. Since coculture cells can further oxidize LDL during

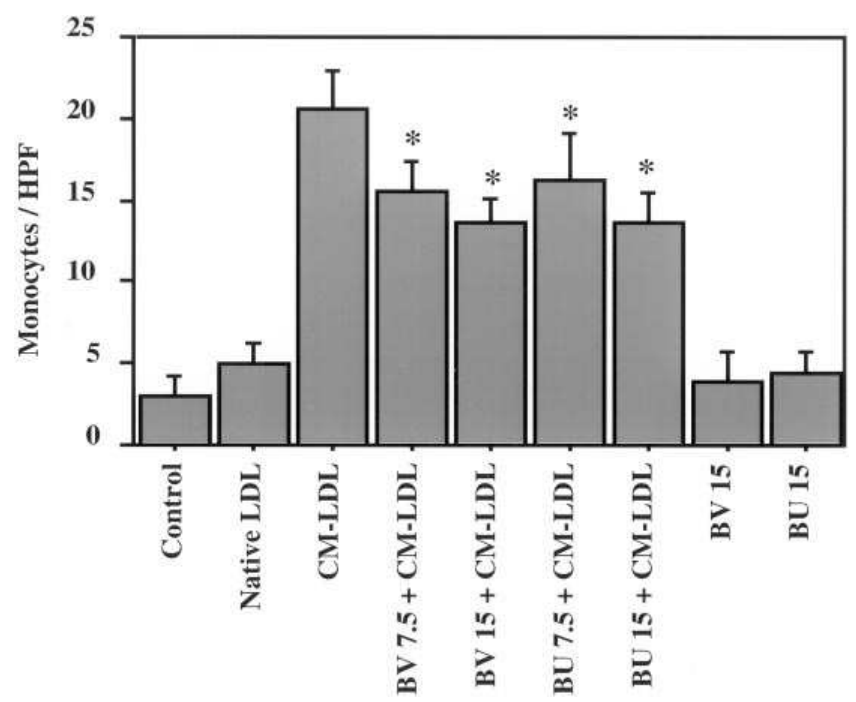

Figure 5. Pretreatment with bilirubin or biliverdin attenuates monocyte chemotaxis induced by CM-LDL. Coculture cells were pretreated with 7.5 or $15 \mu \mathrm{M}$ bilirubin $(B U)$ or biliverdin $(B V)$ for $2 \mathrm{~h}$. Cells were then exposed to CM-LDL $(350 \mu \mathrm{g} / \mathrm{ml})$ together with bilirubin or biliverdin for another $16 \mathrm{~h}$. Native LDL $(350 \mu \mathrm{g} / \mathrm{ml})$ was used as control. Conditioned medium was collected, and monocyte transmigration assay was performed. Values are mean $\pm \mathrm{SD}$ of the number of migrated monocytes. *Statistically significant differences from CM-LDL treatment $(P<0.001)$. Data shown represent four independent experiments. 


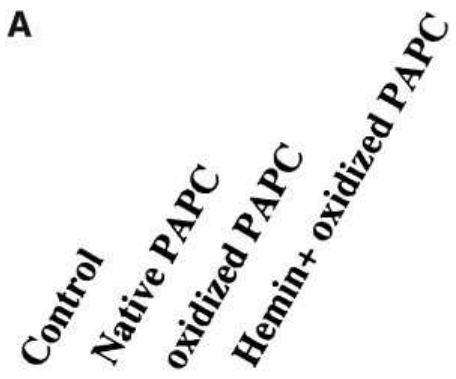

B
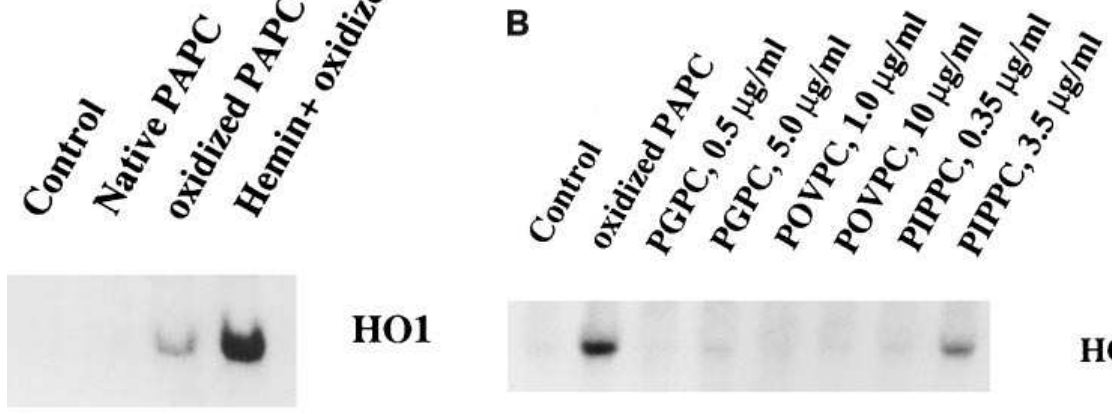

HO1
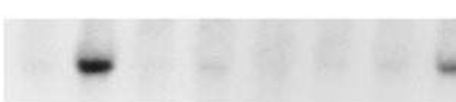

$\alpha$-actin

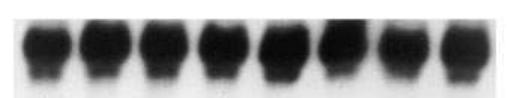

Figure 6. HO-1 mRNA after treatment with oxidized phospholipids. Northern blot analysis was performed using total RNA $(20 \mu \mathrm{g})$ from cocultures. Data shown represent three independent experiments. (A) HO-1 mRNA induction by PAPC. Cocultures were exposed to native (100 $\mu \mathrm{g} / \mathrm{ml})$ or oxidized PAPC $(100 \mu \mathrm{g} / \mathrm{ml})$ for $6 \mathrm{~h}$. Hemin pretreatment was performed at $5 \mu \mathrm{M}$ for $16 \mathrm{~h}$ followed by addition of oxidized PAPC $(100 \mu \mathrm{g} / \mathrm{ml})$ for $6 \mathrm{~h}$. (B) HO-1 mRNA response to biologically active oxidized phospholipids isolated from oxidized PAPC. Cocultures were exposed to oxidized PAPC at $100 \mu \mathrm{g} / \mathrm{ml}$, PGPC at 0.5 or

$\alpha$-actin $\quad 5 \mu \mathrm{g} / \mathrm{ml}$, POVPC at 1.0 or $10 \mu \mathrm{g} / \mathrm{ml}$, and PIPPC at 0.35 or $3.5 \mu \mathrm{g} / \mathrm{ml}$ for $6 \mathrm{~h}$. the incubation, newly formed oxidized LDL may evoke the HO-1 gene response continuously $(32,33)$. A study of HO-1 expression in response to copper-oxidized LDL yielded similar results in porcine aortic smooth muscle cell cultures $(38,39)$. In this study, we observed that this induction also occurred in monolayers of HAEC and HASMC cultured separately (Fig. 4). Although the biologically active species in oxidized LDL has not been characterized completely, we recently demonstrated that oxidized PAPC, which is one of the oxidized phospholipids in mildly oxidized LDL, exhibits biological properties similar to those of mildly oxidized LDL, including the ability to induce monocyte adhesion and chemotaxis (49). Oxidized PAPC also induced HO-1 and augmented induction of HO-1 in the presence of hemin in a manner similar to oxidized LDL (Figs. $2 B$ and $6 A$ ). In addition, HO-1 was induced by PIPPC and PGPC, the biologically active phospholipids isolated from oxidized PAPC (Fig. $6 \mathrm{~B}$ ). The concentration of these three species of oxidized phospholipids used in our studies were sufficient to induce monocyte binding to endothelial cells (50). Though we used a higher molar ratio of PGPC and POVPC than PIPPC due to the availability of the compounds, PIPPC was the most active for HO-1 induction. PIPPC has also been shown to be the most potent inducer of monocyte adhesion to endothelial cells among the three phospholipids (50).

HO-1 is transcriptionally activated through several regulatory mechanisms by a variety of physical and chemical stresses $(2,5,6,8-11)$. Studies of the promoter region of HO-1 revealed transcriptional responsive elements including AP-1 (55-57), AP-2 (57), NF-кB (57), and IL-6 responsive elements (8). These transcriptional factors are known to be activated in inflammatory processes and by oxidative stress. However, the transcriptional regulatory element of the HO-1 gene induced by mildly oxidized LDL has not been identified. In this study, we used hemin to augment HO-1. Recently, Alam and colleagues $(55,58)$ have identified a heme responsive element at $-4 \mathrm{~kb}$ and $-10 \mathrm{~kb}$ in the mouse HO-1 gene. They reported that the heme responsive element contains extended AP-1 as well as the sequences of an oxidative stress responsive element. Understanding the transcriptional regulation of $\mathrm{HO}-1$ gene by hemin and mildly oxidized LDL is important since our data suggest that $\mathrm{HO}-1$ may function as an antioxidant in artery wall cells.

Under our experimental conditions, augmented induction of HO-1 by prolonged incubation with hemin at low concentrations followed by incubation with CM-LDL was observed only in HAEC and not in HASMC (Fig. 4). There are several possible explanations for this difference. One is endothelial cell-specific transcriptional regulation of HO-1. Another is a more rapid hemin uptake by HAEC than by HASMC, or the presence of a putative specific hemin receptor on HAEC. Similar sensitization by heme or hemoglobin against oxidative stresses such as hydrogen peroxide or LPS protects against cytotoxicity, and it was suggested that intracellular ferritin induction may be responsible for cellular protection $(14,15,20)$. In addition, different transcriptional responses of HO-1 in endothelial and smooth muscle cells exposed to hypoxia have been reported (59). Hypoxia increased HO-1 mRNA levels in smooth muscle cells and, conversely, suppressed them in endothelial cells. These results imply that the regulation of HO-1 differs in endothelial and smooth muscle cells, and that the cells may be playing a different role in the protection of the artery wall against these stresses.

Our data indicate that the induction and inhibition of HO-1 affect mildly oxidized LDL-induced monocyte chemotaxis (Figs. 2 and 3). As monocyte diapedesis into artery wall has been considered a key step for atherosclerotic lesion formation, HO-1 may play a role in inhibiting lesion progression. Furthermore, addition of deferoxamine during the pretreatment with hemin markedly reduced the monocyte chemotaxis induced by CM-LDL. This may be because deferoxamine chelated ferric iron released by the $\mathrm{HO}$ reaction or, alternatively, deferoxamine attenuated the subsequent oxidation of CM-LDL during incubation, resulting in decreased biological activity. Agarwal et al. (39) previously reported that pretreatment of human umbilical vein endothelial cells with deferoxamine attenuated HO-1 induction in response to oxidized LDL. However, the addition of deferoxamine during hemin pretreatment did not alter the CM-LDL-induced HO-1 mRNA expression in our experiments (data not shown). These differing results are probably explained by the fact that our experiments involved 
hemin pretreatment. We previously observed higher HO-1 induction in the atherosclerosis-susceptible inbred mouse strain C57/BL6J than in the resistant strain $\mathrm{C} 3 \mathrm{H} / \mathrm{HeJ}$ after feeding with an atherogenic high-fat diet (60). Also, we recently observed HO-1 expression in the aortic atherosclerotic lesions of apo E knockout mice by immunohistochemistry. ${ }^{3}$ These data suggest that HO-1 is induced and involved in the process of lesion formation in vivo. The overall significance of HO-1 induction in the process of atherosclerosis is not clear. However, our data reveal that HO-1 may be one of the protective factors in atherogenesis acting by inhibiting oxidized LDL-induced monocyte extravasation. Recent immunohistochemical studies demonstrated that HO-2 is constitutively expressed in the endothelial cells of porcine pulmonary artery (26). However, HO-2 is a constitutive enzyme not likely to be induced by oxidized lipids. Analyses using transgenic or gene-targeted mice of these isoforms of $\mathrm{HO}$ will be necessary to clarify the actual role of this enzyme.

The mechanism by which HO-1 induction results in the attenuation of oxidized LDL-induced monocyte transmigration is not fully elucidated. Our results showed that both biliverdin and bilirubin moderately reduce the level of monocyte chemotaxis. Biliverdin is one of the $\mathrm{HO}$ reaction products, and bilirubin is the metabolite of biliverdin, produced by biliverdin reductase in the cytosol of mammals $(1,16)$. Bilirubin has been considered a waste product of heme degradation or a toxic substance. However, Stocker et al. (21) demonstrated that both bilirubin and biliverdin exhibit antioxidant properties in inhibiting the oxidation of linoleic acid by peroxyradical. A series of biochemical studies revealed that bilirubin can inhibit the production of hydroxyperoxides of phospholipids, triglycerides, or cholesterol esters by the radicals generated from neutrophils (61), and that it can inhibit the formation of oxidized LDL in vitro (22-24). Although we did not directly measure the bilirubin or biliverdin concentrations in the media, our experiments suggest that biliverdin and bilirubin produced either from the augmented HO-1 reaction or administered exogenously are used as antioxidants. The levels of biliverdin in the cocultures would be expected to be low due to the presence of biliverdin reductase, which converts it to bilirubin. The steady state levels of bilirubin may also be low because it is likely to be rapidly consumed as an antioxidant.

Recent population studies reported that higher plasma concentration of bilirubin may be an independent negative risk factor for coronary artery disease $(62,63)$. Understanding that atherosclerosis is brought about by continuous oxidative stress to the artery wall leads to the concept that the endogenous antioxidant pathways may be playing important roles. It is tantalizing to suggest that enhancement of HO-1 expression with nontoxic stimuli in atheroma or in the vessel after vascular intervention may retard the process of atheroma formation or restenosis. Further studies of the transcriptional regulation of HO-1 by oxidized lipids and of the relationship of heme and lipid metabolism will be of interest.

\section{Acknowledgments}

We thank Dr. Judith Berliner, Dr. Peter Edwards, Dr. Andrew D. Watson, and Dr. Tadashi Yoshida for valuable discussions; Susan Y.

3. Ishikawa, K., manuscript in preparation.
Hama-Levy, Cheryll Cardinez, Bobby Harris, Marie-Luise Brennan, and Alan Wagner for excellent technical assistance; and the members of the UCLA Heart Transplant team for collecting the aortic specimens.

This work was supported in part by a National Institutes of Health grant (HL-30568), by the Laubisch, Rachel Israel Berro, and M.K. Grey Funds (RR865), and by the Cigarette Tobacco Surtax Fund of the State of California through the Tobacco-related Disease Research Program at the University of California. K. Ishikawa is a fellow of the Japanese Heart Foundation.

\section{References}

1. Tenhunen, R., H.S. Marver, and R. Schmid. 1969. Microsomal heme oxygenase. Characterization of the enzyme. J. Biol. Chem. 244:6388-6394.

2. Shibahara, S., R.M. Muller, and H. Taguchi. 1987. Transcriptional control of rat heme oxygenase by heat shock. J. Biol. Chem. 262:12889-12892.

3. Cruse, I., and M.D. Maines. 1988. Evidence suggesting that the two forms of heme oxygenase are products of different genes. J. Biol. Chem. 263:33483353.

4. Maines, M.D. 1988. Heme oxygenase: function, multiplicity, regulatory mechanisms and clinical application. FASEB (Fed. Am. Soc. Exp. Biol.) J. 2: 2557-2568.

5. Taketani, S., H. Kohno, T. Yoshinaga, and R. Tokunaga. 1989. The human $32-\mathrm{kDa}$ stress protein induced by exposure to arsenite and cadmium ions is heme oxygenase. FEBS (Fed. Eur. Biochem. Soc.) Lett. 245:173-176.

6. Keyse, S.M., and R.M. Tyrrell. 1989. Heme oxygenase is the major 32$\mathrm{kDa}$ stress protein induced in human skin fibroblasts by UV radiation, hydrogen peroxide and sodium arsenite. Proc. Natl. Acad. Sci. USA. 86:99-103.

7. Kutty, R.K., C.N. Nagineni, G. Kutty, J.J. Hooks, G.J. Chader, and B. Wiggert. 1994. Increased expression of heme oxygenase-1 in human retinal pigment epithelial cells by transforming growth factor-beta. J. Cell. Physiol. 159: 371-378.

8. Cantoni, L., C. Rossi, M. Rizzardini, M. Gadina, and P. Ghezzi. 1991. Interleukin-1 and tumor necrosis factor induce hepatic haem oxygenase. Biochem. J. 279:891-894.

9. Morita, T., M.A. Perrella, M. Lee, and S. Kourembanas. 1995. Smooth muscle cell-derived carbon monoxide is a regulator of vascular cGMP. Proc. Natl. Acad. Sci. USA. 92:1475-1479.

10. Lee, P.J., J. Alam, S.L. Sylvester, N. Inamdar, L. Otterbein, and A.M.K. Choi. 1996. Regulation of heme oxygenase-1 expression in vivo and in vitro in hyperoxic lung injury. Am. J. Respir. Cell Mol. Biol. 14:556-568.

11. Yoshida, T., P. Biro, T. Cohen, R.M. Muller, and S. Shibahara. 1988. Human heme oxygenase cDNA and induction of its mRNA by heme. Eur. J. Biochem. 171:457-461.

12. Noguchi, M., T. Yoshida, and G. Kikuchi. 1983. A stoichiometric study of heme degradation catalyzed by the reconstituted heme oxygenase system with special consideration of the production of hydrogen peroxide during the reaction. J. Biochem. (Tokyo). 93:1027-1036.

13. Balla, G., G.M. Vercellotti, U. Muller-Eberhard, J. Eaton, and H.S. Jacob. 1991. Exposure of endothelial cells to free heme potentiates damage mediated by granulocytes and toxic oxygen species. Lab. Invest. 64:648-655.

14. Balla, J., H.S. Jacob, S. Balla, K. Nath, J.W. Eaton, and G.M. Vercellotti. 1993. Endothelial-cell heme uptake from heme proteins: induction of sensitization and desensitization to oxidant damage. Proc. Natl. Acad. Sci. USA. 90:9285-9289.

15. Balla, G., H.S. Jacob, J. Balla, M. Rosenberg, K. Nath, F. Apple, J.W. Eaton, and G.M. Vercellotti. 1992. Ferritin: a cytoprotective antioxidant stratagem of endothelium. J. Biol. Chem. 267:18148-18153.

16. Fakhrai, H., and M.D. Maines. 1992. Expression and characterization of a cDNA for rat kidney biliverdin reductase. Evidence suggesting the liver and kidney enzymes are the same transcript product. J. Biol. Chem. 267:4023-4029.

17. Abraham, N.G., Y. Lavrovsky, M.L. Schwartzman, R.A. Stoltz, R.D. Levere, M.E. Gerritsen, S. Shibahara, and A. Kappas. 1995. Transfection of the human heme oxygenase gene into rabbit coronary microvessel endothelial cells: protective effect against heme and hemoglobin toxicity. Proc. Natl. Acad. Sci. USA. 92:6798-6802.

18. Vogt, B.A., J. Alam, A.J. Croatt, G.M. Vercellotti, and K.A. Nath. 1995 Acquired resistance to acute oxidative stress. Possible role of heme oxygenase and ferritin. Lab. Invest. 72:474-483.

19. Lee, P.J., J. Alam, G.W. Wiegand, and A.M.K. Choi. 1996. Overexpression of heme oxygenase-1 in human pulmonary epithelial cells results in cell growth arrest and increased resistance to hyperoxia. Proc. Natl. Acad. Sci. USA. 93:10393-10398.

20. Otterbein, L., S.L. Sylvester, and A.M.K. Choi. 1995. Hemoglobin provides protection against lethal endotoxemia in rats: the role of heme oxygenase-1. Am. J. Respir. Cell Mol. Biol. 13:595-601.

21. Stocker, R., Y. Yamamoto, A.F. McDonagh, A.N. Glazer, and B.N. Ames. 1987. Bilirubin is an antioxidant of possible physiological importance. Science (Wash. DC). 235:1043-1046. 
22. Neuzil, J., and R. Stocker. 1994. Free and albumin-bound bilirubin are efficient co-antioxidants for alpha-tocopherol, inhibiting plasma and low density lipoprotein lipid peroxidation. J. Biol. Chem. 269:16712-16719.

23. Wu, T.-W., K.-P. Fung, and C.-C. Yang. 1994. Unconjugated bilirubin inhibits the oxidation of human low density lipoprotein better than trolox. Life Sci. 54:477-481.

24. Hulea, S.A., E. Wasowicz, and F.A. Kummerow. 1995. Inhibition of metal-catalyzed oxidation of low-density lipoprotein by free and albuminbound bilirubin. Biochim. Biophys. Acta. 1259:29-38.

25. Verma, A., D.J. Hirsch, C.E. Glatt, G.V. Ronnett, and S.H. Snyder. 1993. Carbon monoxide: a putative neural messenger. Science (Wash. DC). 259: 381-384

26. Zakhary, R., S.P. Gine, J.L. Dinerman, M. Ruat, N.A. Flavahan, and S.H. Snyder. 1996. Heme oxygenase-2: endothelial and neuronal localization and role in endothelium-dependent relaxation. Proc. Natl. Acad. Sci. USA. 93: 795-798.

27. Suematsu, M., S. Kashiwagi, T. Sano, N. Goda, Y. Shinoda, and Y. Ishimura. 1994. Carbon monoxide as an endogenous modulator of hepatic vascular perfusion. Biochem. Biophys. Res. Commun. 205:1333-1337.

28. Johnson, R.A., M. Lavesa, B. Askari, N.G. Abraham, and A. Nasjletti. 1995. A heme oxygenase product, presumably carbon monoxide, mediates a vasodepressor function in rats. Hypertension (Dallas). 25:166-169.

29. Christodoulides, N., W. Durante, M.H. Kroll, and A.I. Schafer. 1995. Vascular smooth muscle cell heme oxygenases generate guanyl cyclase-stimulatory carbon monoxide. Circulation. 91:2306-2309.

30. Steinberg, D., S. Parthasarathy, T.E. Carew, J.C. Khoo, and J.L. Witztum. 1989. Beyond cholesterol. Modifications of low density lipoproteins that increase its atherogenicity. N. Engl. J. Med. 320:915-924.

31. Witztum, J.L., and D. Steinberg. 1991. Role of oxidized low density lipoprotein in atherogenesis. J. Clin. Invest. 88:1785-1792.

32. Morel, D.W., P.E. DiCorleto, and G.M. Chisolm. 1984. Endothelial and smooth muscle cells alter low density lipoprotein in vitro by free radical oxidation. Arteriosclerosis. 4:357-364.

33. Steinbrecher, U.P., S. Parthasarathy, D.S. Leake, J.L. Witztum, and D. Steinberg. 1984. Modification of low density lipoprotein by endothelial cells involves lipid peroxidation and degradation of low density lipoprotein phospholipids. Proc. Natl. Acad. Sci. USA. 81:3883-3887.

34. Ross, R. 1993. The pathogenesis of atherosclerosis: a perspective for the 1990s. Nature (Lond.). 362:801-809.

35. Berliner, J.A., and J.W. Heinecke. 1996. The role of oxidized lipoproteins in atherosclerosis. Free Radical Biol. Med. 20:707-727.

36. Sasahara, M., E.W. Raines, A. Chait, T.E. Carew, D. Steinberg, P.W. Wahl, and R. Ross. 1994. Inhibition of hypercholesterolemia-induced atherosclerosis in the nonhuman primate by probucol. J. Clin. Invest. 94:155-164.

37. Williams, R.J., J.M. Motteram, C.H. Sharp, and P.J. Gallagher. 1992. Dietary vitamin $\mathrm{E}$ and the attenuation of early lesion development in modified Watanabe rabbits. Atherosclerosis. 94:153-159.

38. Siow, R.C.M., T. Ishii, H. Sato, S. Taketani, D.S. Leake, J.H. Sweiry, J.D. Peason, S. Bannai, and G.E. Mann. 1995. Induction of the antioxidant stress proteins heme oxygenase- 1 and MSP23 by stress agents and oxidized LDL in cultured vascular smooth muscle cells. FEBS (Fed. Eur. Biochem. Soc.) Lett. 368:239-242.

39. Agarwal, A., J. Balla, G. Balla, A.J. Croatt, G.M. Vercellotti, and K.A. Nath. 1996. Renal tubular epithelial cells mimic endothelial cells upon exposure to oxidized LDL. Am. J. Physiol. 271:F814-F823.

40. Zhu, W., P. Roma, A. Pirillo, F. Pellegatta, and A.L. Catapano. 1996. Human endothelial cells exposed to oxidized LDL express hsp70 only when proliferating. Arterioscler. Thromb. Vasc. Biol. 16:1104-1111.

41. Tsukamoto, Y., K. Kuwabara, S. Hirota, J. Ikeda, D. Stern, H. Yanagi, M. Matsumoto, S. Ogawa, and Y. Kitamura. 1996. 150-kD oxygen-regulated protein is expressed in human atherosclerotic plaque and allows mononuclear phagocytes to withstand cellular stress on exposure hypoxia and modified low density lipoprotein. J. Clin. Invest. 98:1930-1941.

42. Navab, M., S.S. Imes, S.Y. Hama, G.P. Hough, L.A. Ross, R.W. Bork, A.J. Valente, J.A. Berliner, D.C. Drinkwater, H. Laks, and A.M. Fogelman. 1991. Monocyte transmigration induced by modification of low density lipoprotein in cocultures of human aortic wall cells is due to induction of monocyte chemotactic protein 1 synthesis and is abolished by high density lipoprotein. $J$. Clin. Invest. 88:2039-2046.

43. Navab, M., G.P. Hough, L.W. Stevenson, D.C. Drinkwater, H. Laks, and A.M. Fogelman. 1988. Monocyte migration into the subendothelial space of a coculture of adult human aortic endothelial and smooth muscle cells. $J$. Clin. Invest. 82:1853-1863.
44. Cushing, S.D., J.A. Berliner, A.J. Valente, M.C. Territo, M. Navab, F. Parhami, R. Gerrity, C.J. Schwartz, and A.M. Fogelman. 1990. Minimally modified low density lipoprotein induces monocyte chemotactic protein 1 in human endothelial cells and smooth muscle cells. Proc. Natl. Acad. Sci. USA. 87:51345138 .

45. Quinn, M.T., S. Parthasarathy, L.G. Fong, and D. Steinberg. 1987. Oxidatively modified low density lipoproteins: a potential role in recruitment and retention of monocyte/macrophage during atherogenesis. Proc. Natl. Acad. Sci. USA. 84:2995-2998.

46. Havel, R.J., E.A. Eder, and J.H. Bragdon. 1955. The distribution and chemical composition of ultracentrifugally separated lipoproteins of human serum. J. Clin. Invest. 43:1345-1353.

47. Berliner, J.A., M.C. Territo, A. Sevanian, S. Ramin, J.A. Kim, B. Bamshad, M. Esterson, and A.M. Fogelman. 1990. Minimally modified low density lipoprotein stimulates monocyte endothelial interactions. J. Clin. Invest. 85: 1260-1266.

48. Watson, A.D., M. Navab, S.Y. Hama, A. Sevanian, S.M. Prescott, D.M Stafforini, T.M. McIntyre, B.N. La Du, A.M. Fogelman, and J.A. Berliner. 1995. Effect of platelet activating factor-acetylhydrolase on the formation and action of minimally oxidized low density lipoprotein. J. Clin. Invest. 95:774-782.

49. Watson, A.D., J.A. Berliner, S.Y. Hama, B.N. La Du, K.F. Faull, A.M. Fogelman, and M. Navab. 1995. Protective effect of high density lipoprotein associated paraoxonase. J. Clin. Invest. 96:2882-2891.

50. Watson, A.D., N. Leitinger, M. Navab, K.F. Faull, S. Hörkkö, J.L. Witztum, W. Palinski, D. Schwenke, R.G. Salomon, W. Sha, et al. 1997. Structura identification by mass spectrometry of oxidized phospholipids in minimally oxidized low density lipoprotein that induce monocyte/endothelial interactions and evidence for their presence in vivo. J. Biol. Chem. 272:13597-13607.

51. Fogelman, A.M., K. Sykes, B.J. Van Lenten, M.C. Territo, and J.A. Berliner. 1988. Modification of the Recalde method for the isolation of human monocyte. J. Lipid Res. 29:1243-1247.

52. Ishikawa, K., M. Sato, and T. Yoshida. 1991. Expression of rat heme oxygenate in Escherichia coli as a catalytically active, full-length form that binds to bacterial membranes. Eur. J. Biochem. 202:161-165.

53. Lowry, O.H., N.J. Rosebrough, A.L. Farr, and R.J. Randall. 1951. Protein measurement with the folin phenol reagent. J. Biol. Chem. 193:265-275.

54. Navab, M., S.Y. Hama, B.J. Van Lenten, D.C. Drinkwater, H. Laks, and A.M. Fogelman. 1993. A new antiinflammatory compound, leumedin, inhibits modification of low density lipoprotein and the resulting monocyte transmigration into the subendothelial space of cocultures of human aortic wall cells. $J$. Clin. Invest. 91:1225-1230.

55. Alam, J., J. Cai, and A. Smith. 1994. Isolation and characterization of the mouse heme oxygenase-1 gene: distal $5^{\prime}$ sequences are required for induction by heme or heavy metals. J. Biol. Chem. 269:1001-1009.

56. Alam, J., and Z. Den. 1992. Distal AP-1 binding sites mediate basal level enhancement and TPA induction of the mouse heme oxygenase- 1 gene. $J$. Biol. Chem. 267:21894-21900.

57. Lavrovsky, Y., M.L. Schwartzman, R.D. Levere, A. Kappas, and N.G. Abraham. 1994. Identification of binding sites for transcription factors NFkappa B and AP-2 in the promoter region of the human heme oxygenase 1 gene. Proc. Natl. Acad. Sci. USA. 91:5987-5991.

58. Inamdar, N.M., Y.I. Ahn, and J. Alam. 1996. The heme-responsive element of the mouse heme oxygenase- 1 gene is an extended AP-1 binding site that resembles the recognition sequences for MAF and NF-E2 transcription factors. Biochem. Biophys. Res. Commun. 221:570-576.

59. Morita, T., and S. Kourembanas. 1995. Endothelial cell expression of vasoconstrictors and growth factors is regulated by smooth muscle cell-derived carbon monoxide. J. Clin. Invest. 96:2676-2682.

60. Liao, F., A. Andalibi, F.C. deBeer, A.M. Fogelman, and A.J. Lusis. 1993. Genetic control of inflammatory gene induction and NF-кB-like transcription factor activation in response to an atherogenic diet in mice. J. Clin. In vest. 91:2572-2579.

61. Frei, B., R. Stocker, and B.N. Ames. 1988. Antioxidant defenses and lipid peroxidation in human blood plasma. Proc. Natl. Acad. Sci. USA. 85:97489752

62. Schwertner, H.A., W.G. Jackson, and G. Tolan. 1994. Association of low serum concentration of bilirubin with increased risk of coronary artery disease. Clin. Chem. 40:18-23.

63. Hopkins, P.N., L.L. Wu, S.C. Hunt, B.C. James, G.M. Vincent, and R.R. Williams. 1996. Higher serum bilirubin is associated with decreased risk for early familial coronary artery disease. Arterioscler. Thromb. Vasc. Biol. 16:250 255 . 